\title{
Product Development Using Bio-mimicry Design Spiral Approach of Swimming Aid
}

\author{
Ratna Purwaningsih ${ }^{1,}$, Danu Rahardjo ${ }^{2}$, Wiwik Budiawan ${ }^{3}$, Purnawan Adi Wicaksono $^{4}$, and Haryo Santosa ${ }^{5}$ \\ ${ }^{1,2,3}$ Department of Industrial Engineering, Faculty of Engineering, Diponegoro University, Semarang - Indonesia
}

\begin{abstract}
In the search for sustainable products idea, Bio-mimicry is one of the method to find alternative solutions. Bio mimicry is a method to define solution that is filtered and developed by nature. This study used bio mimicry technology to formulate a model of "hand swimming aids" to increase hands thrust in the water when swimming. The proposed model is based on the use of the Bio mimicry Design Spiral rule. Spiral Bio mimicry Design Rules used to simulate the shape and functional design of selected natural organisms. This study learn how frog lining model help frog to swim and select one model and apply it on hand swimmer tool design so that it can produce more sustainable products and can apply the design function of natural model well.
\end{abstract}

Keywords: Bio mimicry; Design Spiral; Swimming aids on hand

\section{INTRODUCTION}

Today, many inventions lead to sports. One sporting practice that produces many inventions of assistive devices is swimming. Swimming is a way that people or animals do to move their bodies in the water [1]. Swimming naturally does not require special equipment or clothing. Humans can swim without any equipment under any circumstances. Swimming devoted to recreation and sports. Swimming in the military sometimes require additional equipment in the form of clothing and special equipment designed to help facilitate humans moving in the water. Some of the additional equipment that is already there and often used when swimming is swimming glasses, torpedoes (simple /motor), ear and nose cover, head cover, swimsuit, and frog legs. Additional equipment designed to accelerate the movement of humans in the water, usually intended for swimming and competition activities. However, swimming equipment is designed to make it easier to swim and avoid the risks arising from swimming.

The purpose of designing the swimming aids on the hands is to facilitate the thrust and make the movement more efficient during swimming. Hand movements have an influence in swimming activities. The design of swimming aids are mostly done by using bio-mimicry approach. Examples are frog legs aid that mimic the function of frog legs, fins that mimic the functions of whale tail plates, and swimsuits of athletes that mimic the concept of shark scales. Design of a swimming aids that focus on hand tools is mimicking the concept of frog membrane on frog legs.

Bio-mimicry is an innovation approach that gradually becomes more popular. The term bio-mimicry was popularized through a book "Bio mimicry: Innovation Inspired by Nature". The focus is on finding sustainable solutions to human challenges by looking at nature as "model, size, and mentor". Frogs have solved many of the problems we face today. The way frogs solve problems has been developed throughout history to generate new solutions and innovations. An example is, the frog's legs on the type of tree frog are imitated into mini-robots for surgical devices that have hexagonal legs and can stick to wet or even slippery surfaces. Another example is the frog's nest, where some frogs make nests like foams. Scientists mimicking those principles to be artificial foams in the laboratory. The foam will withstand the damage caused by bacteria and microbes and also be able to retain moisture.

The design process follows the Bio-mimicry Design Spiral rule through the Challenge to Biology approach published by the Biomimicry Institute. Spiral Biomimicry Design was developed by Carl Hastrich who is an industrial designer. Spiral Biomimicry Design is the stage of the process for transforming natural strategies into innovative and sustainable design solutions. In the revised Biomimicry Design Spiral there are 5 processes, namely distill, translate, discover, emulate, and evaluate [2]. One of the most powerful aspects of Biomimicry Design Spiral is the spiral process itself. Spiral models form repetitions in each round, allowing researchers to create more innovative and effective designs. Through the spiral process, researchers can start from the stage that is most appropriate to the condition of the study. If the researcher begins the design of the peneiti design, it can be expanded from the distill process. If you want to create something new or deepen innovation that is inspired from nature, it can start from

\footnotetext{
* Corresponding author: danu.raharja02@gmail.com
} 
the discover process. When starting with assessing and focusing the concept of sustainability on existing products then researchers can start from the evaluation process.

The purpose of this study is learn on how to apply Bio-mimicry Design Spiral rules into the design process of swimming aids on hand by mimicking the principles of frog foot lining and to knowing the application of Bio-mimicry Design Spiral rules in product design. The output of the study is to describe on how to use the rules of bio-mimicry spiral design in designing the sustainable product.

\section{Literature Review}

Research on biomimicry already done area of architecture [3] and Interior Design for increased the product sustainability [4], [5]. Biomimicry also applied on children's educational playground [6]. The use of biomimicry in the design of swimming aids is still a challenging topic.

\subsection{The concept of Bio-mimicry}

Bio-mimicry in Europe commonly called bionic is a design that is inspired by nature. Bio-mimicry does not merely imitate but the inspiration for changing the principles of nature into successful design strategies. Bio-mimicry technology uses nature as a model, then measures, and trains us to overcome problems in architecture. This is not the same as the biomorphic architecture, which uses the existing elements of nature as a source of inspiration for creating shapes. Biomimicry technology just look at nature as an example that can be used as inspiration, see the process of nature, then apply it into a work [7].

Nature is inspiring not only because of its perfection, but because nature produces a lot. There are some flaws in natural design: natural products require ongoing and / or reproducible maintenance, and organisms cannot borrow designs; they must evolve from their existing designs. Evolution requires solutions to be better than ever; this is not a test ground for new strategies that might get worse for generations before they get better. However, whatever we see in nature has been tested for hundreds or thousands of years, and the earth has provided innumerable intelligent solutions that we might never have imagined.

Three main factors that describe this new field of study. First, bio-mimicry studies natural models and imitates or draws inspiration from its designs to process human problems. Second, bio-mimicry uses ecological standards to assess the 'truth' of human-made innovations. And thirdly, bio-mimicry becomes a new way of seeing and appreciating nature. Bio-mimicry introduces an era, not on what we can take from nature, but what we can learn from nature [8].

The core idea of bio-mimicry is as a model, a measure, and a mentor. By using nature as a model, we can get ideas to solve our problems from organisms. Whatever we try to do, there are usually organisms that have developed successful strategies for doing so.
Applying nature as a measure, we can look at the natural world to see what is possible. Spider webs are, for example, cobwebs, stronger than steel and stronger than Kevlar (which claims to be five times stronger than steel), but the "factory" that produces it is smaller than our pinkie, and does not require boiling sulfuric acid or high-pressure engines. Taking nature as a mentor, we can recognize that we are part of a great system, and we are destroying nature as partner / partner and teacher rather than as a source to be exploited.

Bio-mimicry can be achieved at different levels: the level of shape and function, process level, and system level. The shape and function of bio-mimicry applied on Velcro is the most common embodiment of bio-mimicry. Biomimetic processes make products as nature wants. Making their own layers developed in the national laboratory of the Sandia Department of Energy is an example of a biometric process-they evolved from a solution of how shellfish grows in seawater. Incredibly powerful, transparent coatings, which can be developed rapidly in the laboratory, can revolutionize any kind of cover for everything from cars to contact lenses. Biomimetic systems display a closed loop cycle of life that recycles the outputs and products of one process as inputs for the other. In the biomimetic system "waste equals food" [9]. We can add another Level Four: design level. Biomimetic design processes in forms such as genetic algorithms and repetition designs-can produce cheap and green results that we never see in nature. The students of nature learn quickly.

\subsection{The Bio-mimicry Design Spiral}

The Bio-mimicry Institute has developed a design process that can promote the transfer of ideas, designs, and strategies from biology into the design of human systems. The Bio-mimicry Process Design describes a step to translate the problem in biological terms, thus bringing more opportunities for biologists to identify innovative solutions in nature. The steps in this process are also graphically depicted in the so-called "Spiral Design Bio-mimicry" shown below. The image communicates repeatedly (evolving) on the methodological properties by mapping steps based on the spiral design on the snail's shell. Snail shell (Nautilus shell) is a proper symbol, it is based on a spiral design with a ratio found throughout the natural design and human design. This redesign pattern consists of a series of so glowing productive Fibonacci measurements, dubbed "The Golden Ratio".

The design of bio-mimicry spiral describe on figure 1. The process or stage start from identify the problem or the user need identification that should be solve in the design. Stage 2 is Translate, this stage try to find the solution from nature to answer the problem. Continue by observe stage, the stage identify nature model for the solution. Then the nature model applied on design concept in the emulate stage. The evaluate stage will evaluate the design to make any adjustment by considering the human or user, the material, the method how to use the product. 


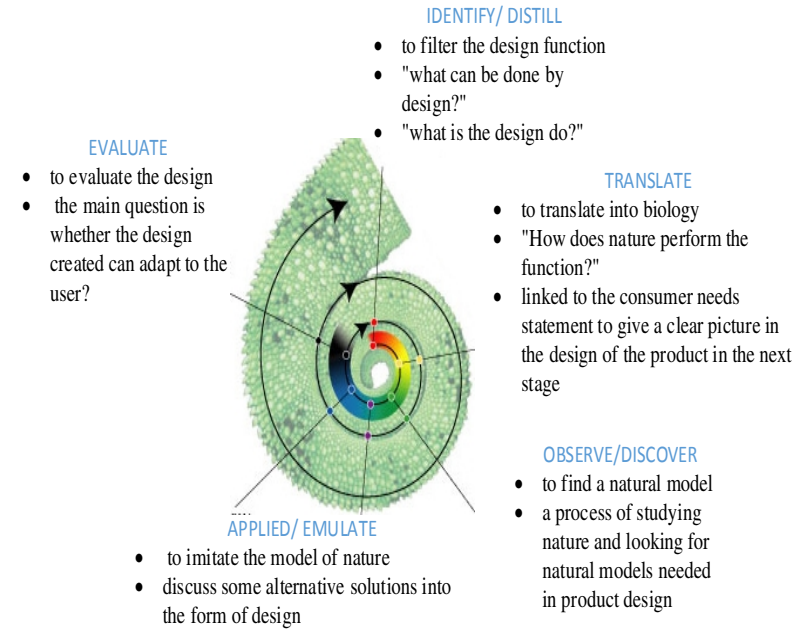

Fig. 1. The Design Spiral

Spiral Bio-mimicry Design is the stage of the process for transforming natural strategies into innovative and sustainable design solutions. There are 5 processes in the revised Bio-mimicry Design Spiral: distill, translate, discover, emulate, and evaluate. One of the most powerful aspects of Bio-mimicry Design Spiral is the spiral process itself. Spiral models form repetitions in each round, allowing designer to create more innovative and effective designs. Through the spiral process, designer can start from the stage that is most appropriate to the condition of the study. If the designer begins the design, they can be expanded from the distill process. If you want to create something new or great innovation that is inspired from nature, you can start from the discover process. If designer start with assessing and focusing the concept of sustainability of existing products then he can start from the evaluation process.

The Biomimicry Design Spiral concept, the researcher starts from the evaluate process, then distill, translate, discover, emulate, and finally return to the evaluate stage. This is because, the researchers found the product of handmade swimming aids on the existing hand and circulating in the market, so that the first process is evaluate where researchers will conduct assessment and focus the concept of sustainability on existing products. These products include paddle boards, finger lining, and swimming gloves. In the present study, the researchers attempted to systematically apply how the product design uses the rules of biomimicry spiral design on hand swimming aids.

The spiral model is also a flexible process, so it can be started from any step. If you want to create something new design, then researchers can start from the stagedistill. If interested in deepening innovation, such as sustainable design and provide solutions, it can be started from the translate process. If the goal is creativity, then it can start from the emulate process. And if starting with assessing and focusing the concept of sustainability on existing products, then researchers can start from the evaluation process.

\section{Research Method}

Research using the Biomimicry Design Spiral concept starts from the evaluate process, then distill, translate, discover, emulate, and finally return to the evaluate stage. This is because, the researchers found the product of handmade swimming aids on the existing hand and circulating in the market, so that the first process is evaluate where researchers will conduct assessment and focus the concept of sustainability on existing products. These products include paddle boards, finger lining, and swimming gloves. In the present study, the researchers attempted to systematically apply how the product design uses the rules of biomimicry spiral design on hand swimming aids.

\subsection{Di-still}

Distill or here is meant to filter the design function, in the distill process, the main question point is "what can be done by design?", And no longer question "what is the design do?". So at this stage, the design function is identified, so that it can then be linked to the consumer needs statement to give a clear picture in the design of the product in the next stage.

In the process of distill identification is done to formulate the problem faced. Do not ask what you want to design (a hand-held swimming tool), but ask what the design is doing for you (provides a stronger thrust force in the water to increase swimming speed). Ask the "why" question of the problem formulation and keep asking the question, to conclude how the desired design is to answer the emerging problem.

\subsection{Translate}

Translate or here it is intended to translate into biology, at this stage the design function has been filtered developed into the natural factors. The main question is "How does nature perform the function?". From these questions it is necessary to define the natural conditions that reflect the design parameters.

This process learn how nature can accommodate humans in swimming, focusing on hand tools. In this process is done to identify the desired function. Then describe what nature is doing to perform the function. Then describe influential environmental factors / conditions, then connect to what nature can do with that factor.

\subsection{Discover}

Discover or here is meant to find a natural model, is a process of studying nature and looking for natural models needed in product design. Natural model in the search is a model capable of performing such design functions. After studying the factors that influence the hand gestures while swimming, designer observe the environment and look for objects that can provide solutions. Then after found, it will be done in-depth observation

\subsection{Emulate}

Emulate or here in question is to imitate the model of nature, in it contains activities to discuss some alternative solutions into the form of design in 
accordance with the design functions. The shape of the design mimics the natural model that has been selected. The result of observation to the object of research will be imitated and applied to product design to be made. Then tested the design.

\subsection{Evaluate}

Evaluate or here is meant to evaluate the design, the main question is whether the design created can adapt to the user? Initial stage evaluation is an initial stage assessment process conducted on the existing swimming hand tool product to know the value given by the user based on the dependent variable so as to know the weakness and the advantages of the product to get the design according to the needs and wants of the user. The intended user is a swimmer who has used a paddle board product, and / or a swimming glove product, and / or a finger film product. The selected design will be evaluated in detail, with a direct test of swimming swim measurements, and then an interview to get an assessment of whether the design is in accordance with the consumer needs or not.

\section{Result and discussion}

The Biomimicry Design Spiral concept, the researcher starts from the evaluate process, then distill, translate, discover, emulate, and finally return to the evaluate stage. This is because, the researchers found the product of handmade swimming aids on the existing hand and circulating in the market, so that the first process is evaluate where researchers will conduct assessment and focus the concept of sustainability on existing products. These products include paddle boards, finger lining, and swimming gloves. In the present study, the researchers attempted to systematically apply how the product design uses the rules of biomimicry spiral design on hand swimming aids.

Nature has the slightest influence in human life. No exception in swimming activities. The natural factors that influence the activity of swimming (especially in hand movements) are environment, water flow, water depth, and the movement of other objects.

Discover is a process of finding solutions that exist in nature that match human needs that have been translated into the translate process. In this step, will be classified several types of animals that swim using a tool of motion of the hands or feet of animals belonging to the classification of vertebrate animals (vertebrates) that exist around the researchers.

Designer found some animals that used to do swimming activities. The researcher's focus is to observe how the animal performs the activity in the water and whether the motion used has similar function to the researcher's design function. Frogs have hands and feet used during swimming. The goose and duck forces only use their feet to pedal the water so they can float and move in the water. The three animals perform the same function with the researcher's design function, which is moving in water by enlarging the thrust force in the water. The motion of frog swim in the water while membrane in the frog's legs docked and stretched. Differ to the ducks and swans that are mostly always stretched and just doing the paddling motion. These observations bring the designer decision to focus on frog animals as the model that best adapts to the functioning of the human hand.

The frog pushes its legs back, then the membrane opens, creating a dam against water. When the frog pulls the leg back to its body, the membrane closes, streamlining the movement of the foot through the water back to its original position. And the hand movements tend to be straight forward. The webbed feet increase the area of propulsion (encouragement) to allow the frog to swim quickly. Frogs are famous amphibians that can jump and swim very well with the same rear-legged mechanisms, so it is important to learn the mechanics of motion to realize the ability of motion in an unstructured field. In frog swims, the joints rotate in large numbers, and due to the movement of the limbs, the frog can perform repeated routes. Here is a picture of the area of impulse (boost) generated from the back leg kick of the frog while swimming [10].

In this study, the function of addition of propulsion will be made as a reference in forming the design of swimming aids on hand. Where in the activity of human swimming, the four tools of motion with both hands and both feet active and play a role in swimming. But researchers will only focus on hand gestures, because the tools of swimming on the feet are common in the market. However, swimming aids on hand have not been found. The occurrence of additional propulsion on the swimming frog movement, not apart from the membrane on the frog legs. Because the membrane provides a wider cross section so as to increase the strength of the surrounding water.

The principle of frog foot lining that is able to provide propulsion while swimming in the water, can affect the speed of swimming. The principle will be applied to the hand swimming aids. Where the hand can provide a more optimal propulsion if it has a crosssectional area maximized by the width of the hand so as to produce a greater thrust force than the empty hand.

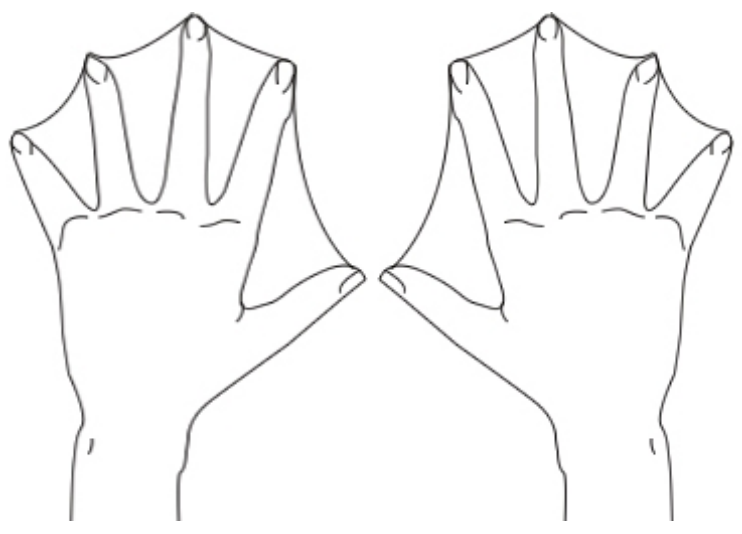

Fig 2. The membrane on hand copy of frog foot lining

By using bio mimicry, by studying natural design features and applying them into product design as 
problem solvers, able to provide attractive solutions that can be applied and explored to achieve optimal design.

Imitate the membrane function in frog legs suggest to faster swimming. Frogs that stretch their webbed legs wider, allowing it to apply more force to the surrounding water. The wider the surface the greater the power generated. Leg muscle strength also plays a role, frogs with greater leg muscle strength which isn't webbed have weaker thrust against water than frogs with weak legs but have a membrane on their feet. As the frog pushes back with its legs, the membrane opens, creating a dam against water. When the frog pulls the leg back to its body, the membrane closes, streamlining the movement of the foot through the water back to its original position.

\section{Acknowledgments}

Researchers would like to thank to Diponegoro University student and all the people involved for the cooperation for this study. This research was financially supported by the Research and public service Directorate of Ministry of Research Technology and Higher Education in scheme of PTUPT (Penelitian Terapan Unggulan Perguruan Tinggi) 2018

\section{References}

1. E. C. Badruzaman, \& A. Hernawan Media and learning resource for play group Jakarta: Universitas Terbuka (2007)
2. Hastrich, Carl, "The Bio mimicry Spiral," Biomimicry Newsletter, the Bio mimicry Guild, Vol. 4.1. (2006)

3. E. Zejnilović., \& E. Husukić, E. Biomimicry in Architecture. International Journal of Engineering Research and Development, Volume 11, PP.75-84 (2015)

4. I. H. Anous Biomimicry"Innovative Approach in Interior Design for Increased Sustainability. American International Journal of Research in Formal, Applied \& Natural Sciences , pp. 18-27. (2015).

5. D. Attia, Biomimicry In Eco - Sustainable Interior Design: Natural Ventilation Approach . Faculty of Applied Arts, Benha University : International Design Journal, Volume 5, Issue 2, pp 291-303 (2015)

6. Haslina, R. Jurnal Tingkat Sarjana Senirupa dan Desain No.1 ITB (2014)

7. J. Benyus. Biomimicry: Innovation Inspired by Nature. New York: William Morrow (2002).

8. A. J. Brookes and D. Poole. Innovation in Architecture: A Path to the Future 1st Edition, Spon press New York (2004)

9. M. William \& M. Braungart. Cover of Cradle to Cradle: Remaking the Way We Make Things. United States: North Point Press (2002)

10. W. Zhang, J. Fan, Y. Zhu, Y. Qiu, \& J. Zhao. A Method for Mechanism Analysis of Frog Swimming Based on Motion Observation Experiments. Heilongjiang: Hindawi Publishing Corporation (2014) 